\title{
A Survey on Chinese College English Teachers' Conceptions of Research and Research Engagement ${ }^{*}$
}

\author{
SUN Xiaohui \\ Beijing Normal University, Beijing, China
}

\begin{abstract}
This paper investigated 70 Chinese college English teachers' conceptions of research and research engagement. Questionnaire and interview were used to collect data. The findings of this study show that college English teachers have an understanding of research and can realize the importance of scientificity and understand characteristics of good quality research. In addition, although some college English teachers can realize the importance of research on their own learning and professional development, their current situations of research engagement in general is not satisfactory.
\end{abstract}

Keywords: college English teachers, teachers' conceptions of research, current situations of teachers' research engagement, teachers as researchers

\section{Introduction}

In the process of curriculum reform, teachers face the transformation of their roles from being passive and submissive to more active and creative. To realize such transformation, one thing teachers should possess is the researcher's perspective, which depends on teachers' knowledge and understanding of research, that is, teachers' conceptions of research. Thus, exploring teachers' knowledge and understanding of research is significant for teachers to adapt themselves to the requirements of curriculum reform and to realize the transformation of their roles. In addition, such an exploration can help teacher educators figure out problems in teacher research, which will ultimately enhance teachers' professional level and promote their professional development.

Many researchers (Everton, Galton, \& Pell, 2000; Ratcliffe et al., 2004; Shkedi, 1998) have carried out surveys on teachers' understanding of research. The idea behind these studies is that teachers' conceptions of research and understanding of their roles in teaching can facilitate teachers' doing research in a better way. In the field of foreign language teachers' teaching, most studies are concerned with the issue of how teachers carry out research. Only a small number of researchers have conducted empirical research on teachers' conceptions of research. For example, Allison and Carey (2007) surveyed 22 Canadian university language teachers and argued that lacking of time and motivation is the main challenge that teachers face in doing research. Borg (2009) investigated the research conceptions of 505 English teachers from 13 countries and figured out that the research conceptions teachers hold are aligned with conventional scientific notions of inquiry. The teachers

\footnotetext{
*Acknowledgement: This paper was supported by "the Fundamental Research Funds for the Central Universities" (No. 005-105573GK). The researcher is grateful for the help. Meanwhile, the researcher also thanks Prof. CHENG Xiaotang, Prof. LUO Shaoqian, and Mr. Chris Tebbe for their good suggestions on this paper.

SUN Xiaohui, Dr., School of Foreign Languages and Literature, Beijing Normal University.
} 
reported that a lack of time, knowledge, and access to material are key factors limiting their ability to be research-engaged. In addition, Tabatabaei and Nazem (2013) investigated 150 English as a Foreign Language (EFL) teachers' conceptions of research and they found teachers' conceptions of research are very close to the conventional scientific theories and findings. Meanwhile, lack of time, knowledge, and institutional support are the influential factors which restrict teachers' abilities to be research-engaged.

Many researchers in China have explored English teachers' current situations of doing research, and have systematically analyzed problems in their research. For instance, Cheng (2010) believed that the main problems in young college English teachers' research include onerous teaching burdens, weak awareness of research, unscientific research methods, indefinite research directions, and insufficient experience on applying for projects. Wang and Han (2011) put forward the prominent problems in Chinese foreign language teachers' research and deeply analyzed the limitations to university foreign language teachers' research development from the four aspects of: (a) discipline construction; (b) Ph.D. student education; (c) academic pace-setter and the backbone force of research construction; and (d) academic journal platform construction. Wu and Zhang (2011) argued that the instrumentalization and commercialization of foreign languages, the metaphysics of foreign language research, and the difficulty of publication of foreign language research findings are the major reasons for the relative low research level of foreign language teachers. In addition, Zhou (2007) conducted a survey and discovered that teachers face the problems of lack of time, inability to do research, and high pressure from school in doing research. At the same time, the results from interviews and questionnaires show that there are obvious differences among teachers in conceptions of and ability in doing research. The majority of the above scholars have explored and analyzed the problems teachers meet in doing research. However, they have paid little attention to how teachers themselves understand research. Hu and Tang (2012) followed Borg's (2009) study and investigated how college English teachers perceive teaching research, teaching research culture and environment, as well as engagement in teaching research based on an emic survey of teachers' conceptions of teaching research. But, in general, studies on teachers' conceptions of research in China are still in the phase of exploring.

In order to better understand Chinese teachers' conceptions of research, this study purposefully selected 70 English teachers from one normal university in the west part of China as participants, and studied their conceptions of research and current situations of their research engagement. It aims to further understand college English teachers' conceptions of research and their puzzlement as researchers, which can help to seek for research methods for them and promote their professional development.

\section{Methods}

\section{Research Questions}

This study proceeded from investigating college English teachers' conceptions of research in one normal university from the west part of China. The specific research questions are as following:

1. What are college English teachers' conceptions of research?

2. What are current situations of college English teachers' research engagement? What are the reasons for their doing and not doing research?

\section{Research Participants}

This study followed purposeful sampling. Emails were sent to those participants, the purpose of this study 
was introduced, and teachers were asked to sign consent forms. Participants' qualification and background information (years of experience, relevant qualification to ELT and time they teach for each week ...) were identified in Section 4 of the questionnaire (see Appendix 1).

\section{Data Collection and Analysis}

Both quantitative and qualitative data were collected in this study. The quantitative data mainly come from the questionnaire result. The questionnaire used in this study was the instrument developed by Borg (2009) and it was slightly modified by the researcher. The questionnaire was piloted with a group of 10 English teachers and its length, wording, and organization were revised and changed based on their feedback and its validity and reliability have already been established by Borg (2009). The questionnaire consisted of four parts. The first part was composed of both closed and open questions. The rest three parts were all closed questions. The qualitative data came from interviews and open questions in the questionnaire.

Seventy questionnaires were sent out and all the questionnaires had been withdrawn. The quantitative data was numbered and recorded, and then, analyzed by using Excel. Qualitative data were analyzed based on Creswell (2007), and Bogdon and Biklen (1992). Through coding the qualitative data, identifying the common meaningful units and themes, generalizing, analyzing, and categorizing the data, the researcher finally got the research results.

\section{Findings and Discussion}

\section{College English Teachers' General Conceptions of Research}

In order to investigate college English teachers' conceptions of research, this study designed 10 scenarios based on Borg's (2009) questionnaire (see Appendix 1), requiring participants to analyze these 10 scenarios and judge whether they belong to research or not. As defining research is a very difficult task, in order to ensure the survey is scientific and appropriate, the researcher has provided four choices of different degrees. In addition, in each scenario, there is an open question, requiring participants to give reasons for their choices. These open questions can compensate for multiple questions, so that the researcher can understand teachers' conceptions of research in a more direct, comprehensive, and authentic way.

College English teachers' judgment of the 10 scenarios is shown in the following Figure 1 (Data in Figure 1 is presented in percentage):

According to Figure 1, we can see that most teachers choose the 8th scenario not to be a research. By analyzing the interview data, the researcher find out that the reasons teachers provide for their choices include the following aspects:

(1) The research method is not rigorous. (No. 2)

(2) There is no complete research design and procedure. The sample is too small, which cannot be said to be representative, for example:

Only five participants provided feedback, which cannot indicate anything, and it is inappropriate to make out research plans based on five people's information. (No. 12)

This is only an informal way to know students' situation, and the number of students involved is too small. It is smaller than the number of 30 which is a must in quantitative research. (No. 26)

How can five participants' opinions represent 30 students' ideas? The researcher is irresponsible. (No. 34) 


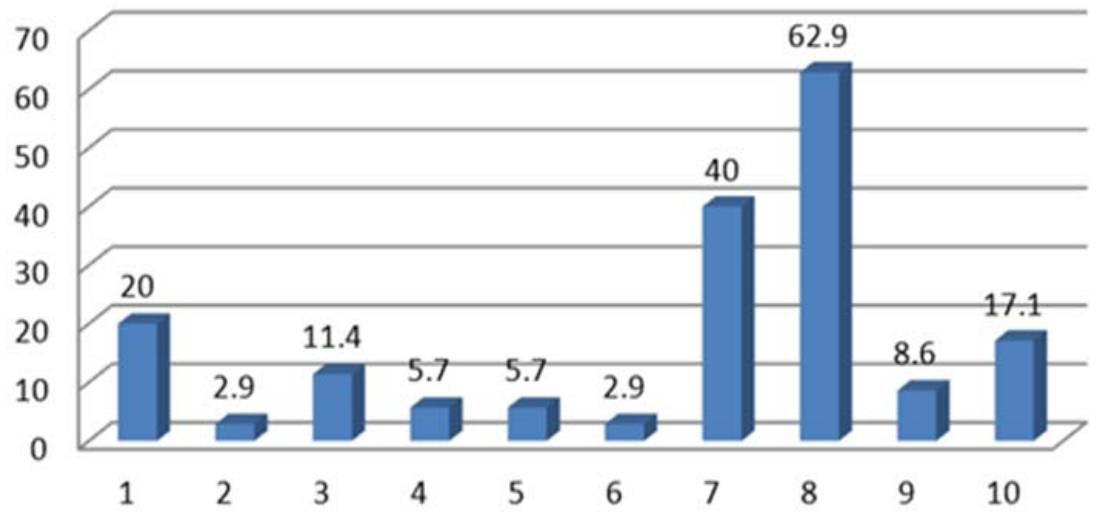

Figure 1. The distribution of "Definitely not research" among 10 scenarios.

(3) This is part of the normal teaching activity or it does not belong to research, for example:

This is part of his normal teaching activity. (No. 1)

This is an ordinary survey. (No. 14)

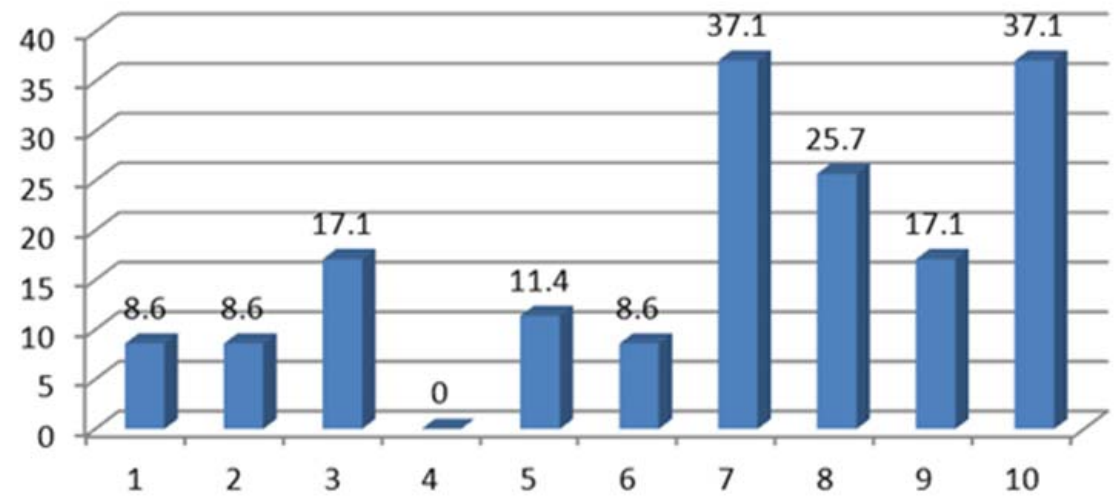

Figure 2. The distribution of "Probably not research" among 10 scenarios.

According to Figure 2, we can see that most teachers think the 7th and the 10th scenarios are "Probably not research." By analyzing the interview data, the researchers conclude the reasons teachers provide for their choices in the 7th scenario as the following:

(1) Strictly speaking, it cannot be said to be research, for example:

It is part of the research using interviews as the data collection tool, but strictly speaking, the conclusion drawn does not belong to research. (No. 4)

(2) It lacks theoretical support and systematic demonstration, for example:

Work reports without theoretical support or systematic demonstration do not belong to research. (No. 35)

The researchers conclude the reasons teachers provide for their choices in the 10th scenario as the following:

(1) It depends on whether there is theoretical support for the survey result, for example:

This may not be research, because it depends on whether it is simply a list of survey results, or whether there is theoretical support for the results. (No. 3) 
(2) This is a survey report. It may not be research, for example:

It belongs to survey reports related to work, because it lacks a complete procedure of research. (No. 45)

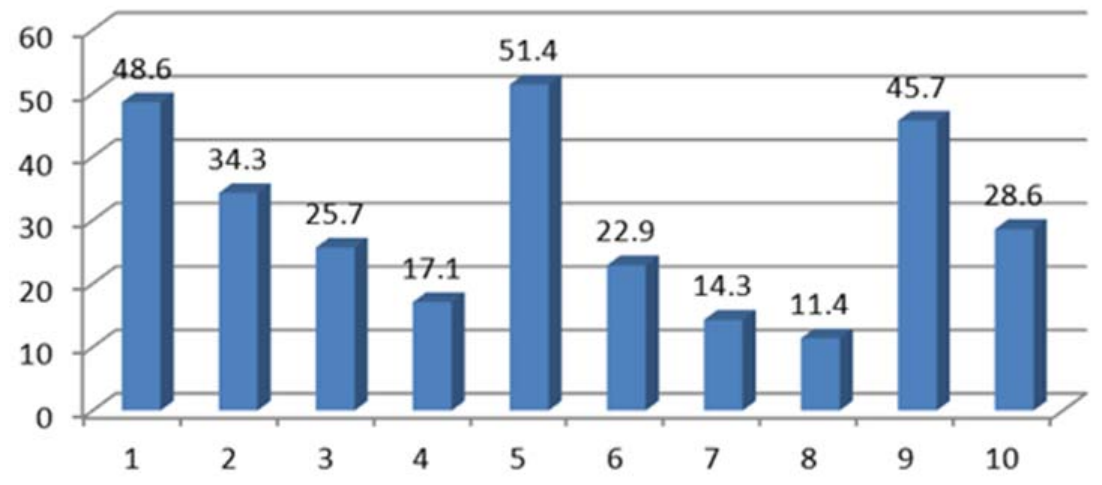

Figure 3. The distribution of "Probably research" among 10 scenarios.

Figure 3 shows that most teachers think that the 5th scenario is the most likely to be a research. By analyzing the interview data, the researchers conclude the reasons teachers provide for their choices as the following:

(1) The demonstration of specific points is very important, for example:

If it is only about feelings and experiences, then it is not research. But if there is demonstration of points, then it is research. (No. 10)

(2) The process of the academic research is incomplete, so it cannot be said to be research, for example:

It may only be several stages of a research. It lacks the complete academic research process required by the modern academic research norm. (No. 36)

(3) A research should be practical, for example:

Researches are not simply a pile of theories. They should be practical. (No. 15)

(4) Regular observation, discussion and publication of the paper may be important parts in research, for example:

There are relatively long time of regular observations, discussions and short essay descriptions, so it may be a research. (No. 52)

According to Figure 4, we can see that most teachers think that the 4th scenario is absolutely a research. By analyzing the interview data, the researchers conclude the reasons teachers provide for their choices as the following:

(1) It belongs to the quantitative research, for example:

This is quantitative research. (No. 30)

This is quantitative research. (No. 43)

(2) It meets the requirements of research, for example:

Both the conduct and method meets the requirements of research. (No. 12) 
(3) The paper has been published and it is practical in a certain sense, for example:

The author puts the idea into practice, and the paper has been published, so it must be a research. (No. 38)

(4) There are the survey, statistics and analyses, for example:

There are the survey, data, analyses, and conclusion, so it is a research. (No. 42)

The data is collected from a big sample and there is the analysis of the data, so it is a research. (No. 50)

There are statistics and analyses, so it is a research. (No. 53)

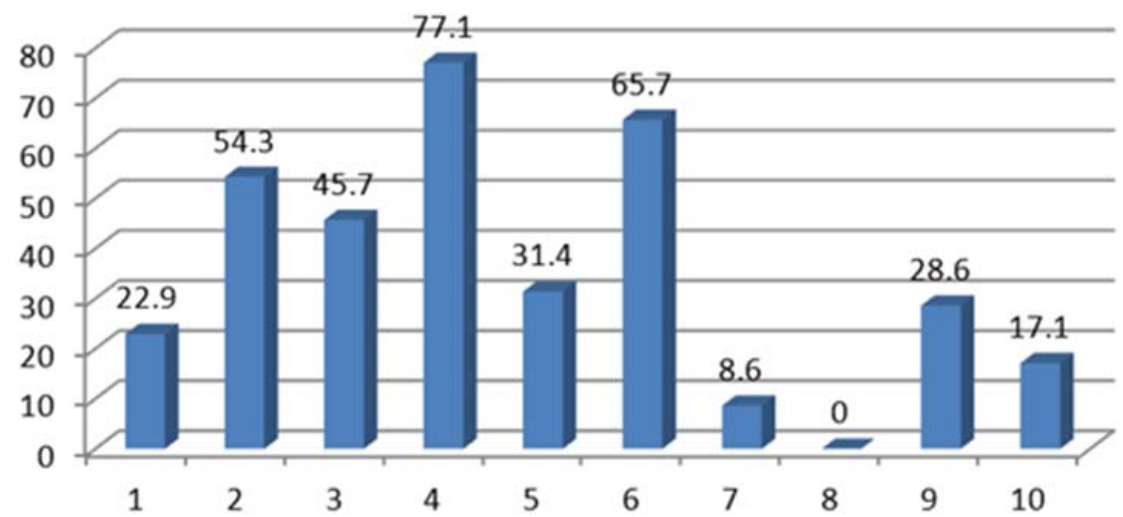

Figure 4. The distribution of "Definitely research" among 10 scenarios.

The above analyses show that college English teachers in general believe that the research method should be rigorous, researches should be based on theories, and researches should be practical. In addition, words like "data, statistics, and analyses" appear in the interview data repeatedly, which show that college English teachers hold clear conceptions of research, and that they have realized the importance of being scientific for a research.

\section{College English Teachers' Conceptions of Characteristics of Good Quality Research}

In order to further understand college English teachers' conceptions of research, 11 research characteristics based on Borg's (2009) questionnaire (see Appendix 1) were conducted which investigated college English teachers' conceptions of characteristics of good quality research in five ratings from "Very important" to "Unimportant." To make the research result more clear, the researchers combined both "Very important" and "Important" into "Important," and both "Moderately important" and "Unimportant" into "Less important." The results are shown in the following figures (Data in Figure 5 is presented in percentage).

From Figure 5, we can see that college English teachers think that the 1st item, that is "A large number of people are studied." And the 10th item, that is, "Questionnaires are used" are the least important two. Some teachers have provided their opinions in interviews, for example:

I think the research can be divided into both the qualitative and the quantitative ones. The participants for the qualitative research need not to be that many. (No. 20)

There must not be questionnaires in a research. The author can also use interviews. (No. 28)

It seems that questionnaires can only be used in quantitative researches. There is hardly any use of them in qualitative researches, unless there are open questions. (No. 65)

According to Figure 6, we can clearly see that college English teachers think that the 7th item, that is, "The researcher is objective" is the most important one. Besides, $85.7 \%$ of the teachers believe that whether the research results can give teachers ideas they can use is also very important. 


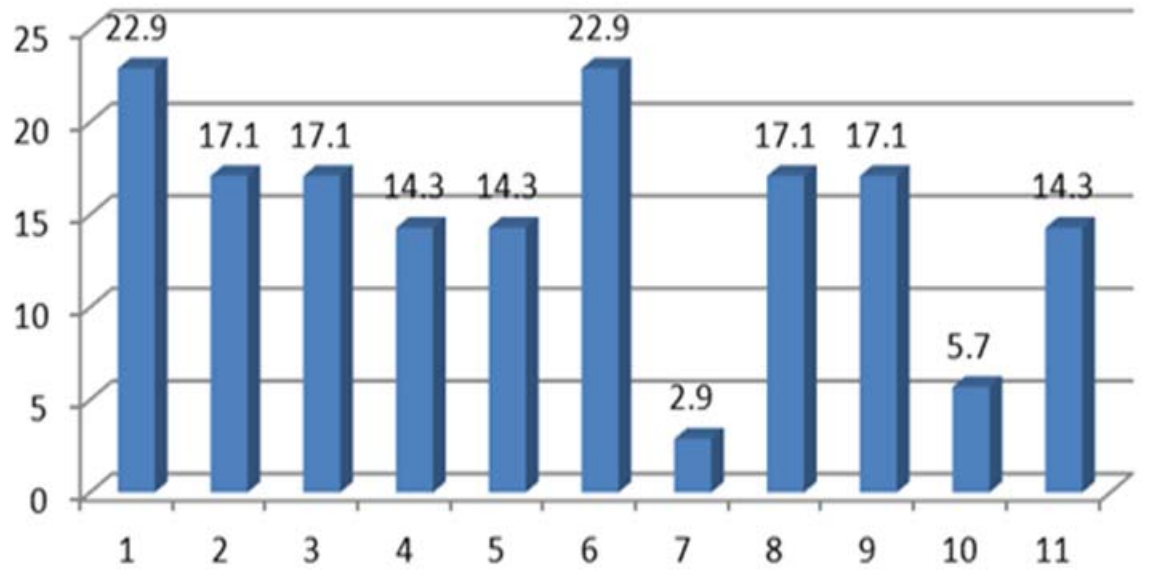

Figure 5. The distribution of "Less important" among 11 research characteristics.

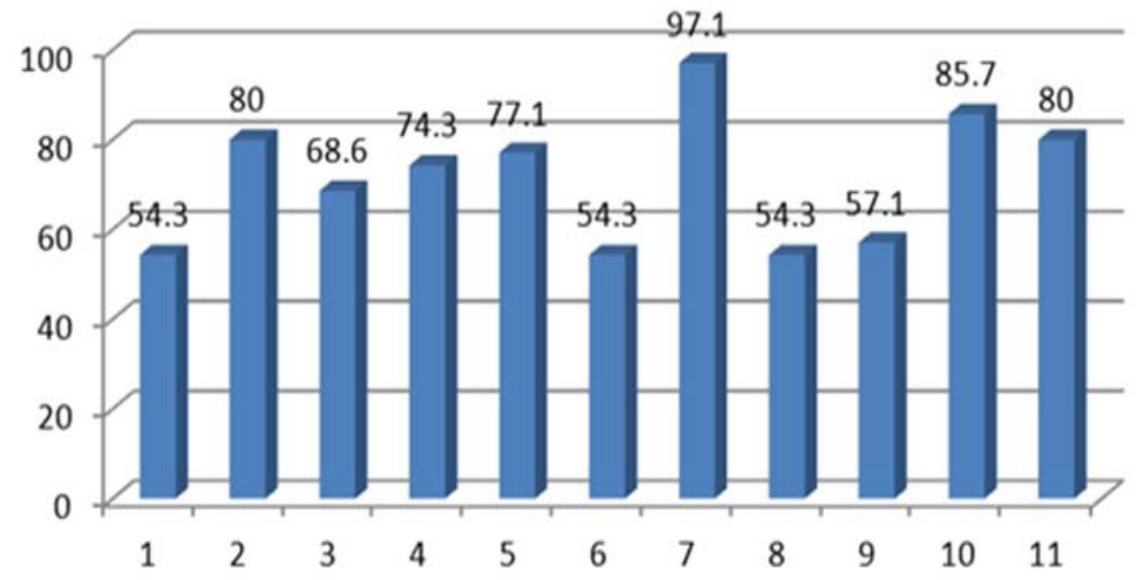

Figure 6. The distribution of "Important" among 11 research characteristics.

Figure 7 indicates that college English teachers are mostly unsure about the 8th item, that is, "The results apply to many ELT contexts." Some teachers have given their opinions in interviews. For example:

I am uncertain about whether research results can be applied into English teaching. Because, nowadays, many researches are unrelated to English teaching. (No. 24)

I only aim at expressing a certain point clearly when writing a paper. I have no idea whether the results can be applied in English teaching. (No. 37)

I read a lot of articles in my daily life, but I have never thought of applying those results into teaching. I only hope to learn how they do research and what they research on. (No. 55)

To conclude, college English teachers hold clear conceptions of research, and they have realized the importance of being scientific for a research. Besides, they have a quite comprehensive understanding of research characteristics. Most of them think that researches do not necessarily adopt the form of questionnaire, however, other methods, such as interviews can be used. Some teachers are not certain about whether research results can be widely applied into English teaching and this presents the current reality that some researches are divorced from teaching. 


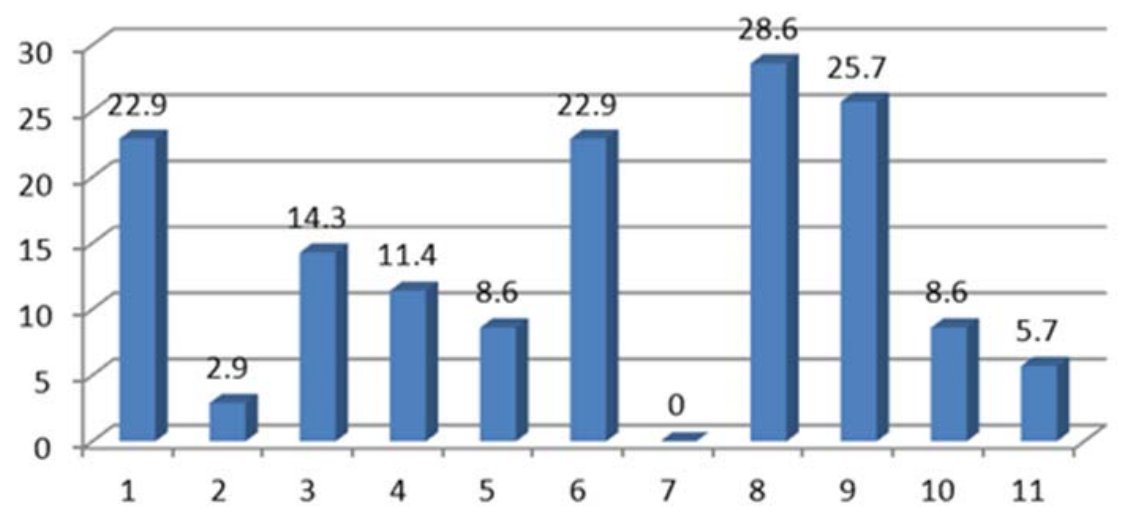

Figure 7. The distribution of "Unsure" among 11 research characteristics.

\section{The Analysis of Current Situations of College English Teachers' Research Engagement}

In order to explore current situations of college English teachers' research engagement, the researchers adopted Borg's (2009) questionnaire (see Appendix 1). Figure 8 shows that among the participants, the ratio of those who never or rarely do research is very high, that is $74.3 \%$.

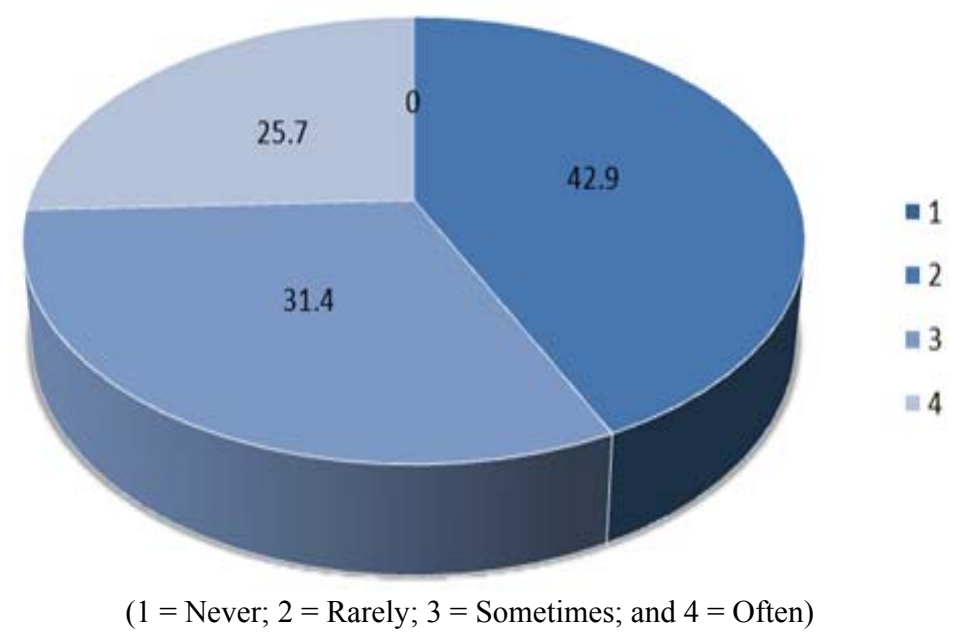

Figure 8. The distribution of current situations of college English teachers' research engagement.

Through Figure 9, it is discovered that teachers think that the 1st item, that is, "As part of a course I am studying on," is very important, which indicates that college English teachers have realized the importance of doing research in their own learning. In addition, the rations of the 3rd item ("Because it is good for my professional development") and the 9th item ("To solve problems in my teaching") are very high. This also shows that college English teachers have realized the influence of doing research on their professional development and the important role of doing research in solving teaching problems.

Figure 10 shows that the main reason why college English teachers never or rarely do research is the $3 \mathrm{rd}$ item ("I do not have time to do research"). As it has been mentioned in the previous part, many scholars have found out that the time issue is the major challenge teachers face in doing research. The researchers think that doing research does cost a large quantity of time, but time should not become an excuse for teachers who rarely or never do research. We should think whether there exists the problem of teachers' weak awareness and low 
interest in doing research behind the statement of "having no time to do research." Besides, the ration of the 4th item ("My employer discourages it") is zero. This reflects that employers of the participants strongly encourage teachers to carry out researches.

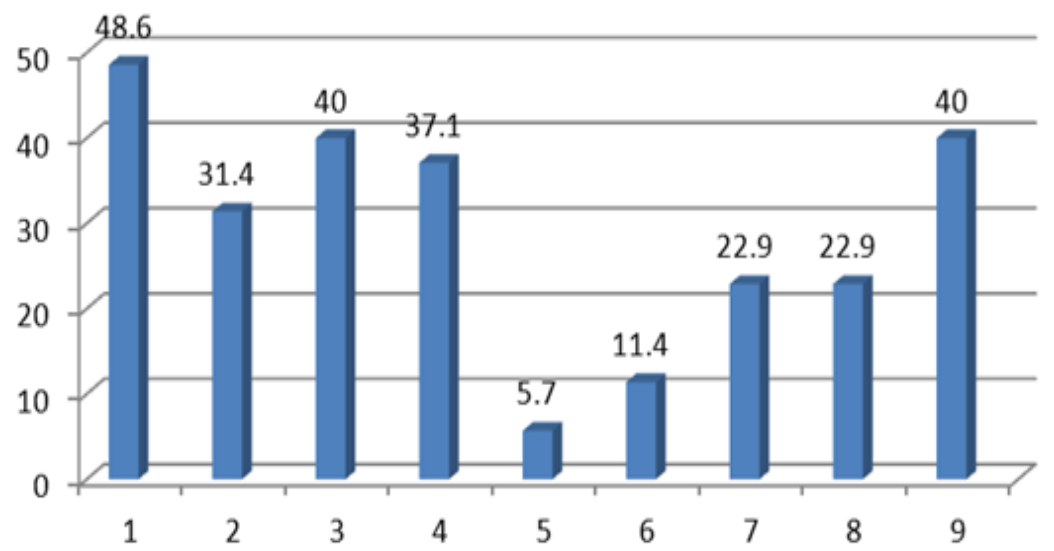

Figure 9. The reason distribution of college English teachers" "Often" or "Sometimes" doing reasearch.

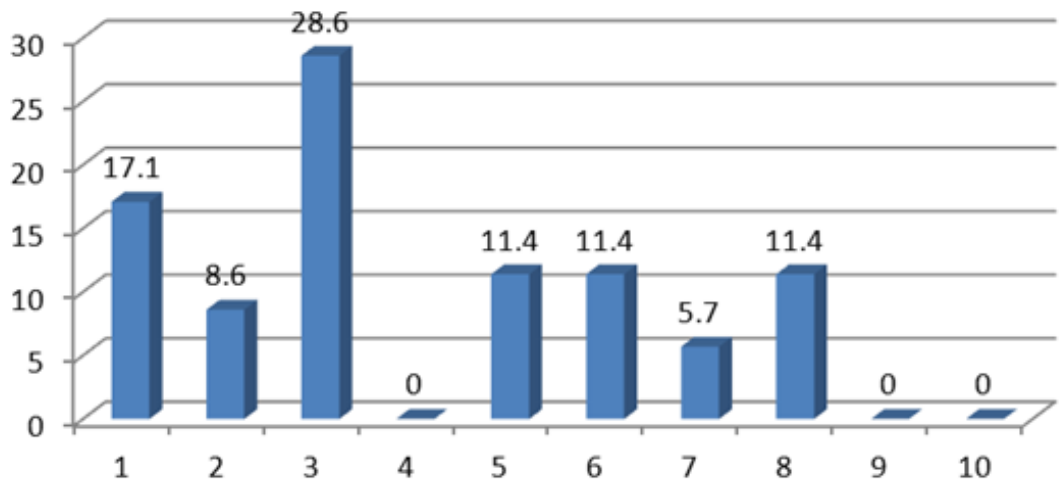

Figure 10. The reason distribution of college English teachers' "Never" or "Rarely" doing reasearch.

From the above analysis, this study finds out that the current situation of the 70 college English teachers' research engagement is not so satisfying. Although the school leaders strongly encourage teachers to do research, the majority of the teachers themselves never or rarely do research.

\section{Conclusion}

This study analyzed research conceptions and current situations of research engagement of 70 college English teachers from one normal university in the west part of China. It shows that:

1. College English teachers hold clear conceptions of research, and they have realized the importance of being scientific for a research.

2. College English teachers have a quite comprehensive understanding of characteristics of good quality research. Most of them think that research do not necessarily adopt the form of questionnaire, however, other methods, such as interviews can be used. Some teachers are not certain about whether research results can be widely applied into English teaching, which presents the current reality that some researches are divorced from teaching. 
3. Current situations of college English teachers' doing research is not so satisfying. The main reason is the claim that "I do not have time to do research." In addition, some teachers have realized the importance of doing research in their own learning and professional development.

Teachers' becoming researchers is an important premise in promoting teachers' professional development. It is hoped that through this study, more teachers can get new understandings and conceptions of research, raise their awareness and interest in doing research, and finally, become a teacher-researcher. The relationship between teaching and doing research is one of the hot topics of college teachers nowadays. This study explores Chinese college English teachers' conceptions and current situations of their research engagement, but it does not mean that college teachers should attach importance to doing research and make light of teaching. Theoretically, teaching and doing research supplement and promote each other (Liu, 2010). Therefore, college English teachers should do well in teaching. And at the same time, they should try to improve their ability in doing research, so that they neglect neither teaching nor doing research.

\section{References}

Allison, D., \& Carey, J. (2007). What do university language teachers say about language teaching research? TESL Canada Journal, 24(2), 61-81.

Bogdon, R. C., \& Biklen, S. K. (1992). Qualitative research for education: An introduction to theory and methods. Boston, MA: Allyn \& Bacon.

Borg, S. (2009). English teachers' conceptions of research. Applied Linguistics, 30(3), 358-388.

Cheng, Q. G. (2010). Problems of young college English teachers' doing research and strategies. China Adult Education, 1, 29-30. (In Chinese)

Creswell, J. W. (2007). Qualitative inquiry and research design: Choosing among five traditions. SAGE Publications.

Everton, T., Galton, M., \& Pell, T. (2000). Teachers' perspectives on educational research: Knowledge and context. Journal of Education for Teaching: International Research and Pedagogy, 26(2), 167-182.

Hu, X. J. \& Tang, X. Y. (2012). An emic survey of college English teachers' conceptions of teaching research. Foreign Language World, 4, 30-38 \& 43.

Liu, Y. (2010). What kind of college teachers can be called qualified teachers. Teacher's Journal, 5, 17.

Ratcliffe, M., Bartholomew, H., Hames, V., Hind, A., Leach, J., Millar, R., \& Osborne, J. (2004). Science education practitioners' views of research and its influence on their practice. York, U.K.: University of York.

Shkedi, A. (1998). Teachers' attitudes towards research: A challenge for qualitative researchers. International Journal of Qualitative Studies in Education, 11(4), 559-577.

Tabatabaei, O., \& Nazem, Y. (2013). English teachers' conceptions of research. Theory and Practice in Language Studies, 3(3), 521-532.

Wang, X. L., \& Han, J. H. (2011). Current situations of Chinese university foreign language teachers' academic research and bottleneck factors from an empirical study perspective. Foreign Language World, 3, 44-51.

Wu, Y. X., \& Zhang, Y. J. (2011). Reflections on improving the research ability of foreign language teachers-Based on the articles published in foreign language world in the past ten years. Theory and Practice of Education, 31(8), 36-39.

Zhou, Y. (2007). A study on college foreign language teachers' developing needs. In Y. A. Wu (Eds.), A study on Chinese college English teacher education and development (pp. 59-102). Beijing: Foreign Language Teaching and Research Press. 


\section{Appendix 1: Questionnaire}

\section{English Teachers' Views of Research}

What does "research" mean to you and what role does it play in your life as a professional English teacher? These are important questions in our field - especially at a time when in many countries, teachers are being encouraged to do research as a form of professional development. You are invited to take 15-20 minutes to show your views on these issues. Participation in this study is voluntary.

Thank you for your interest in contributing.

\section{Section 1: Scenarios}

The purpose of this section is to elicit your views on the kinds of activities which can be called research. There are no right or wrong answers. Read each description below and choose one answer to say to what extent you feel the activity described is an example of research.

1. A teacher noticed that an activity she used in class did not work well. She thought about this after the lesson and made some notes in her diary. She tried something different in her next lesson. This time the activity was more successful.

\begin{tabular}{|ll|ll|ll|l|}
\hline Definitely not research $\quad \square$ & Probably not research $\quad \square$ & Probably research & $\square$ & Definitely research \\
\hline
\end{tabular}

Please state your reasons:

2. A teacher read about a new approach to teaching writing and decided to try it out in his class over a period of two weeks. He recorded some video of his lessons and collected samples of learners' written work. He analyzed this information then presented the results to his colleagues at a staff meeting.

\begin{tabular}{|ll|ll|ll|ll|}
\hline Definitely not research $\quad \square$ & Probably not research & $\square$ & Probably research & $\square$ & Definitely research \\
\hline
\end{tabular}

Please state your reasons:

3. A teacher was doing an MA course. She read several books and articles about grammar teaching then wrote an essay of 6,000 words in which she discussed the main points in those readings.

\begin{tabular}{|lc|lc|lc|l|}
\hline Definitely not research $\quad \square$ & Probably not research $\quad \square$ & Probably research & $\square$ & Definitely research & $\square$ \\
\hline
\end{tabular}

Please state your reasons:

4. A university lecturer gave a questionnaire about the use of computers in language teaching to 500 teachers. Statistics were used to analyze the questionnaires. The lecturer wrote an article about the work in an academic journal.

\begin{tabular}{|ll|ll|ll|ll|}
\hline Definitely not research $\quad \square$ & Probably not research & $\square$ & Probably research & $\square$ & Definitely research & $\square$ \\
\hline
\end{tabular}

Please state your reasons:

5. Two teachers were both interested in discipline. They observed each other's lessons once a week for three months and made notes about how they controlled their classes. They discussed their notes and wrote a short article about what they learned 
for the newsletter of the national language teachers' association.

\begin{tabular}{|ll|ll|ll|l|}
\hline Definitely not research $\quad \square$ & Probably not research & $\square$ & Probably research & $\square$ & Definitely research \\
\hline
\end{tabular}

Please state your reasons:

6. To find out which of two methods for teaching vocabulary was more effective, a teacher first tested two classes. Then, for four weeks, she taught vocabulary to each class using a different method. After that she tested both groups again and compared the results to the first test. She decided to use the method which worked best in her own teaching.

\begin{tabular}{|ll|ll|ll|l|}
\hline Definitely not research $\quad \square$ & Probably not research & $\square$ & Probably research & $\square$ & Definitely research \\
\hline
\end{tabular}

Please state your reasons:

7. A headmaster met every teacher individually and asked them about their working conditions. The head made notes about the teachers' answers. He used his notes to write a report which he submitted to the Ministry of Education.

\begin{tabular}{|ll|ll|ll|l|}
\hline Definitely not research $\quad \square$ & Probably not research $\quad \square$ & Probably research & $\square$ & Definitely research \\
\hline
\end{tabular}

Please state your reasons:

8. Mid-way through a course, a teacher gave a class of 30 students a feedback form. The next day, five students handed in their completed forms. The teacher read these and used the information to decide what to do in the second part of the course.

\begin{tabular}{|ll|ll|ll|l|}
\hline Definitely not research $\quad \square$ & Probably not research & $\square$ & Probably research & $\square$ & Definitely research & $\square$ \\
\hline
\end{tabular}

Please state your reasons:

9. A teacher trainer asked his trainees to write an essay about ways of motivating teenage learners of English. After reading the assignments the trainer decided to write an article on the trainees' ideas about motivation. He submitted his article to a professional journal.

\begin{tabular}{|lc|lc|lc|l|}
\hline Definitely not research $\quad \square$ & Probably not research $\quad \square$ & Probably research & $\square$ & Definitely research \\
\hline
\end{tabular}

Please state your reasons:

10. The head of the English department wanted to know what teachers thought of the new course book. She gave all teachers a questionnaire to complete, studied their responses, then presented the results at a staff meeting.

\begin{tabular}{|ll|ll|ll|l|}
\hline Definitely not research $\quad \square$ & Probably not research & $\square$ & Probablyresearch & $\square$ & Definitely research \\
\hline
\end{tabular}

Please state your reasons: 


\section{Section 2: Characteristics of Good Quality Research}

1. Here is a list of characteristics that research may have. Tick ONE box for each to give your opinion about how important it is in making a piece of research "Good".

\begin{tabular}{|l|l|l|l|l|}
\hline Unimportant & Moderately important & Unsure & Important & Very important \\
\hline 1 & 2 & 3 & 4 & 5 \\
\hline
\end{tabular}

\begin{tabular}{|c|c|c|c|c|c|}
\hline & 1 & 2 & 3 & 4 & 5 \\
\hline \multicolumn{6}{|l|}{ a. A large number of people are studied } \\
\hline \multicolumn{6}{|l|}{ b. A large volume of information is collected } \\
\hline \multicolumn{6}{|l|}{ c. Experiments are used } \\
\hline \multicolumn{6}{|l|}{ d. Hypotheses are tested } \\
\hline \multicolumn{6}{|l|}{ e. Information is analyzed statistically } \\
\hline \multicolumn{6}{|l|}{ f. Questionnaires are used } \\
\hline \multicolumn{6}{|l|}{ g. The researcher is objective } \\
\hline \multicolumn{6}{|l|}{ h. The results apply to many ELT contexts } \\
\hline \multicolumn{6}{|l|}{ i. The results are made public } \\
\hline \multicolumn{6}{|l|}{ j. The results give teachers ideas they can use } \\
\hline k. Variables are controlled & & & & & \\
\hline
\end{tabular}

2. If there are any other characteristics which in your opinion a study must have for it to be called "Good" research, please list them here.

\section{Section 3: Doing Research}

1. How frequently do you do research yourself? (Tick ONE)

\begin{tabular}{|l|l|l|ll|ll|}
\hline Never & $\square$ & Rarely & $\square$ & Sometimes & $\square$ & Often \\
\hline
\end{tabular}

If you chose "Rarely" or "Never" go straight to Question 3 in this section.

2. You said you do research "Often" or "Sometimes". Below are a number of possible reasons for doing research. Tick those which are true for you.

"I do research..."

a. As part of a course, I am studying on.

b. Because I enjoy it.

c. Because it is good for my professional development.

d. Because it will help me get a promotion.

e. Because my employer expects me to

f. Because other teachers can learn from the findings of my work

g. To contribute to the improvement of the school generally

h. To find better ways of teaching.

i. To solve problems in my teaching.

j. Other reasons (Please specify). 
3. You said that you do research "Rarely" or "Never". Below are a number of possible reasons for not doing research. Tick those which are true for you.

"I do not do research, because..."

a. I do not know enough about research methods.

b. My job is to teach not to do research.

c. I do not have time to do research.

d. My employer discourages it.

e. I am not interested in doing research.

f. I need someone to advise me but no one is available.

g. Most of my colleagues do not do research.

h. I do not have access to the books and journals I need.

i. The learners would not co-operate if I did research in class.

j. Other teachers would not co-operate if I asked for their help.

k. Other reasons (Please specify).

\section{Section 4: About Yourself}

1. Your gender: $\square$ Male

$\square$ Female

2. Your age: $\square$ 20-30

$\square 31-40$

$\square$ 41-50

$\square 51-60$

3. Your title: $\square$ Lecturer

$\square$ Associate professor

$\square$ Professor

4. Years of experience as an English teacher (Tick ONE):

$0-4$

$0-4$

5. Highest relevant qualification to ELT (Tick ONE):

\begin{tabular}{|ll|l|ll|ll|ll|ll|}
\hline Certificate $\quad \square$ & Diploma $\quad \square$ & Bachelor's & $\square$ & Master's & $\square$ & Doctorate & $\square$ & Other & $\square$ \\
\hline
\end{tabular}

6. Your teaching time each week:

\begin{tabular}{|l|l|l|l|l|l|}
\hline Below 6 hours $\quad \square$ & $7-10$ hours $\quad \square$ & $11-15$ hours & $\square$ & Above 15 hours \\
\hline
\end{tabular}

7. Your doing research time each week (excluding lesson planning time):

\begin{tabular}{|l|l|l|l|l|l|}
\hline Below 1 hour $\square$ & $1-4$ hours & $\square$ & $5-8$ hours & $\square$ & Above 8 hours \\
\hline
\end{tabular}

This completes the questionnaire. Thank you for taking the time to respond. 